\title{
Genetic Bottlenecks for Two Populations of Ceratocystis fimbriata on Sweet Potato and Pomegranate in China
}

Qian Li, Department of Plant Pathology, China Agricultural University/Key Laboratory of Plant Pathology, Ministry of Agriculture P. R. China, Beijing 100193; Thomas C. Harrington, and Douglas McNew, Department of Plant Pathology and Microbiology, Iowa State University, Ames 50014; Jianqiang Li, Department of Plant Pathology, China Agricultural University, and Beijing Engineering Research Center of Seed and Plant Health/Beijing Key Laboratory of Seed Disease Testing and Control, Beijing 100193; Qiong Huang, College of Plant Protection, Yunnan Agricultural University, Kunming, 650201, P.R. China; Y. M. Somasekhara, Department of Plant Pathology, University of Agricultural Sciences, Bangalore, Karnataka, India; and Acelino C. Alfenas, Departmento de Fitopatologia, Universidade Federal de Viçosa, Minas Gerais, 36570, Brazil

\begin{abstract}
Li, Q., Harrington, T. C., McNew, D., Li, J., Huang, Q., Somasekhara, Y. M., and Alfenas, A. C. 2016. Genetic bottlenecks for two populations of Ceratocystis fimbriata on sweet potato and pomegranate in China. Plant Dis. 100:2266-2274.

Chinese isolates of Ceratocystis fimbriata from sweet potato (Ipomoea batatas) and pomegranate (Punica granatum) were genetically compared with a worldwide collection of isolates from a variety of hosts. Isolates from black-rotted storage roots of sweet potato in China, Japan, Australasia, and the United States had identical internal transcribed spacer (ITS) ribosomal DNA (rDNA) sequences and only minor variation in microsatellite alleles. Sequences of their mating type genes were most similar to those of isolates from various hosts in Ecuador, a center of diversity for sweet potato. Isolates from Colocasia esculenta (taro) and pomegranate from Yunnan and Sichuan had only one ITS rDNA sequence (haplotype

ITS5). This haplotype, sequences of mating type genes, and microsatellite alleles linked these isolates to isolates from Eucalyptus stumps in South China and diseased Eucalyptus trees in Brazil, supporting the hypothesis that the pomegranate population originated from Brazil via cuttings of Eucalyptus. Isolates from sweet potato and pomegranate in China were interfertile with tester strains of $C$. fimbriata, confirming that the causes of the two epidemics in China belong to a single biological species. However, other isolates from Eucalyptus stumps were intersterile with the tester strains and had ITS rDNA sequences typical of the Asian species, C. cercfabiensis.
\end{abstract}

Two major epidemics in China have been associated with Ceratocystis fimbriata, which is a soilborne ascomycete that causes lethal, wilt-type diseases in more than 30 species of woody plants and black rot of several root crops (CABI 2005). It is clear that one or more species of Ceratocystis is the cause of the epidemics on sweet potato (Ipomoea batatas) and pomegranate (Punica granatum) (Huang et al. 2003; Sy 1956) but the proper taxonomic names and likely geographic origins of the pathogens are unclear. The genus Ceratocystis as currently circumscribed (de Beer et al. 2014) is a complex of four geographic clades that differ little in morphology. The North American clade is represented by $C$. variospora, the Asian clade is represented by $C$. pirilliformis, and the African clade is represented by C. albifundus (Johnson et al. 2005, Thorpe et al. 2005). The most aggressive species and strains of the $C$. fimbriata complex are very closely related and appear to be native to the eastern United States and Latin America and, thus, are referred to as the Latin American clade (LAC) (Harrington 2000, 2013; Harrington et al. 2014). Populations of the LAC are genetically diverse and soilborne from Costa Rica to Brazil, and numerous exotic hosts planted in South America have been seriously affected by Ceratocystis wilt (CABI 2005; Ferreira et al. 2010; Harrington 2013). In addition, strains of the LAC are commonly moved to new locations in infected propagative materials, such as cuttings of Eucalyptus and sweet potato storage roots (Engelbrecht et al. 2004, 2007; Ferreira et al. 2010, 2011; Harrington 2013; Ocasio-Morales et al. 2007). Some restrict the name $C$. fimbriata to only isolates from sweet potato, the host from which the species was originally described, and introduced populations of the LAC on other hosts have been given new species names based on

Corresponding authors: T. C. Harrington; E-mail: tcharrin@iastate.edu; and J. Q. Li; E-mail: lijq231@cau.edu.cn

Accepted for publication 2 June 2016.

http://dx.doi.org/10.1094/PDIS-03-16-0409-RE

(C) 2016 The American Phytopathological Society phylogenetic differences (Fourie et al. 2015; Tarigan et al. 2011; van Wyk et al. 2007, 2011, 2012). Others (Harrington et al. 2014; Oliveira et al. 2015b) consider most of these introduced populations of the LAC to be $C$. fimbriata in the strictest sense.

C. fimbriata was first reported in China on sweet potato, on which there were substantial losses of planted cuttings (slips) and a dry, black rot on storage roots (Sy 1956). The pathogen on sweet potato was thought to have been introduced in 1937 from Japan (Sy 1956). There are indications that black rot of sweet potato is caused by a widely distributed strain of $C$. fimbriata, referred to here as the Ipomoea strain (Baker et al. 2003; Engelbrecht and Harrington 2005), but only a limited number of isolates, and none from China, have been studied. More recently, there have been reports of $C$. fimbriata causing a serious wilt on pomegranate in the provinces of Yunnan (Huang et al. 2003) and Sichuan (Xu et al. 2011). The fungus also attacks loquat (Eriobotrya japonica) and causes a postharvest black rot on corms of taro (Colocasia esculenta) in Yunnan; however, serious losses appear to be restricted to pomegranate (Huang et al. 2008; Li et al. 2014a). Harrington et al. (2015) found that isolates from pomegranate and other hosts in Yunnan were genetically similar to isolates from Eucalyptus in Brazil, where Ceratocystis fimbriata is soilborne and native (Ferreira et al. 2011; Harrington et al. 2011; Oliveira et al. 2015a).

It had been suggested that the worldwide population of $C$. fimbriata on Eucalyptus isolates may be C. eucalypticola (van Wyk et al. 2012), a species name that was based on an introduced population in South Africa (van Wyk et al. 2006), and some DNA sequences for Eucalyptus isolates from South China were accessed in GenBank as C. eucalypticola (Harrington et al. 2015). Later, C. acaciivora (Tarigan et al 2011) was identified from stumps of Eucalyptus in Guangdong Province (Chen et al. 2013) but, now, C. acaciivora is considered a synonym of $C$. manginecans (Fourie et al. 2015), which was described from an introduced strain on mango (Mangifera indica) and other hosts in Oman and Pakistan (van Wyk et al. 2007). However, Harrington et al. (2014, 2015) and Oliveira et al. (2015b) consider C. eucalypticola $C$. acaciivora, and $C$. manginecans to be synonyms of $C$. fimbriata. C. fimbriata was reported to cause a lethal wilt disease on Eucalyptus 
isolates in Yunnan (Li et al. 2014b). Other Eucalyptus isolates from stumps in South China were described as a new species, C. cercfabiensis, which appears to be a member of the Asian clade of the $C$. fimbriata complex (Liu et al. 2015). Another new species from the Asian clade, C. collisensis, was described from stumps of Cunninghamia lanceolata in Fujian Province (Liu et al. 2015).

The objective of this study was to genetically analyze isolates of the Ceratocystis fimbriata complex from various hosts in China and compare them with a worldwide collection of representatives of the complex. Specifically, we aimed to (i) determine which of the isolates were $C$. fimbriata through mating studies and phylogenetic analyses, (ii) characterize the diversity of the populations from different locations and hosts using sequences of the internal transcribed spacer (ITS) region of ribosomal DNA (rDNA) and microsatellite (simplesequence repeats [SSR]) analysis, and (iii) identify genetic bottlenecks that may have arisen as strains of the pathogen were moved from location to location in vegetatively propagated host tissue.

\section{Materials and Methods}

Field isolates. Attempts were made to collect isolates of $C$. fimbriata from all known hosts and locations in China. In total, isolates from 10 provinces were studied. Most of the isolates were subcultured from a single mass of ascospores from a selfing to ensure

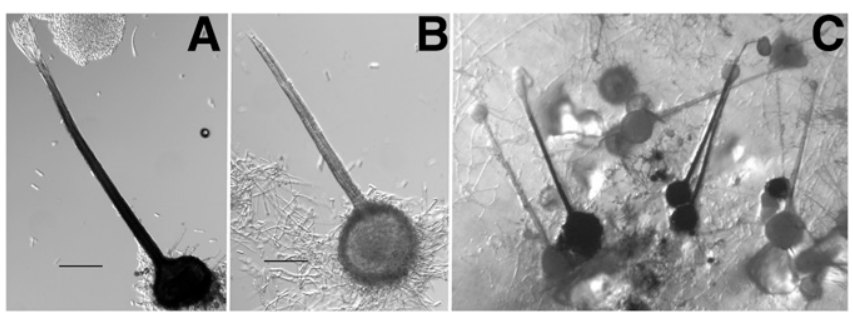

Fig. 1. Perithecia and ascospore masses of Ceratocystis fimbriata produced from crosses of a MAT1/pale mutant (strain C3315) spermatized by a wild-type field isolate (C3308 or C3278). A, Black, wild-type perithecium with ascospore mass at the tip from a cross between C3315 and C3308. B, Pale perithecium from a cross between $\mathrm{C} 3315$ and C3308. C, Pale and black perithecia with ascospore masses resulting from spermatization of the MAT1/pale tester strain used as a female by a MAT2/black, self-fertile strain (C3278) used as a male. Black perithecia are from the selfing of the MAT2/black, male (C3278) and pale perithecia are from the cross between the two strains. Scale bars in A and B are $100 \mu \mathrm{m}$. genetic purity (Witthuhn et al. 2000). In all, 12 isolates were obtained from diseased sweet potato storage roots sold in markets in six provinces in eastern, northern, and southcentral China: 1 from a market in Ningbo City (Zhejiang Province); 2 each from markets in Shijiazhuang City (Hebei Province), Zhengzhou City (Henan Province), Jinan City (Shandong Province), and Mianyang City (Sichuan Province); and 3 from a market in Kunming City (Yunnan Province). Pieces of black-rotted storage root were placed on fresh slices of carrot and, subsequently, ascospore masses on top of perithecia that formed on the carrot slices were streaked onto potato dextrose agar (PDA; $20 \%$ potato infusion, $2 \%$ dextrose, and $1.5 \%$ agar). The Chinese Ipomoea isolates, two new isolates from two separate vendors in Indonesia (Sumatra), and an isolate (C4135) from a market in Hilo, HI were compared with previously studied (Baker et al. 2003; Johnson et al. 2005; Steimel et al. 2004) Ipomoea isolates from around the world: C926 (CBS 141.37) from Maryland; seven isolates (C1416 to -22) from a grower's field in North Carolina, including C1421 (CBS 114723); C854 from Louisiana; C1473 (ICMP 894), C1474 (ATCC 13323), and C1475 (ICMP 1731) from New Zealand; C1476 (ICMP 85790) and C1932 (DAR 58857) from Papua New Guinea; and C1390 (IFO 30501), C1354 (KFCF 9210), and C1869 from Japan. Each isolate was from a separate storage root and all but the collections from North Carolina and China were from a unique vendor or farmer's field.

In addition to 2 isolates from loquat and 27 previously studied isolates (Harrington et al. 2015) from pomegranate in Mengzi County (Honghe Prefecture, Yunnan Province) and 6 isolates from taro corms collected at a distribution facility near Kunming, Yunnan, 5 new isolates were obtained from pomegranate trees in one plantation of Mengzi County, and 3 new isolates were obtained from blackrotted taro corms purchased from a local vendor in a market in Kunming. The isolates were obtained by placing discolored host tissue on PDA. Six new isolates were obtained from pomegranate trees in one plantation in Panzhihua City (Sichuan Province) using the carrot baiting technique (Xu et al. 2011).

Forty-one isolates of the $C$. fimbriata complex were obtained from fresh stumps of Eucalyptus in harvested plantations in four South China provinces in two previous studies (Chen et al. 2013; Liu et al. 2015) using 2\% malt extract and $1.5 \%$ agar. These 41 isolates from the China Eucalyptus Research Centre included 10 isolates $(\mathrm{CERC} 2125$ to $-9=\mathrm{C} 3291$ to -5 and CERC2070 to $-4=\mathrm{C} 3360$ to -4) from three stumps (the distance between stumps was less than $100 \mathrm{~m}$ ) in one plantation in Qionghai City, Hainan Province;

Table 1. Internal transcribed spacer (ITS) ribosomal DNA haplotypes and sexual compatibility with MAT1 and MAT2 tester strains for populations of Ceratocystis fimbriata and C. cercfabiensis in China

\begin{tabular}{|c|c|c|c|c|c|}
\hline \multirow[b]{2}{*}{ Species, hosts } & \multirow[b]{2}{*}{ Location } & \multirow[b]{2}{*}{ Haplotype $^{\mathbf{a}}$} & \multicolumn{3}{|c|}{ Number of isolates } \\
\hline & & & Tested $^{b}$ & MAT1c & MAT2 $^{\text {d }}$ \\
\hline \multicolumn{6}{|l|}{ C. fimbriata } \\
\hline \multirow{5}{*}{ Eucalyptus spp. } & Qionghai, Hainan & ITS5 (AM29204) & 10 & 9 & 1 \\
\hline & Qingyuan, Guangdong & ITS5 & 5 & 2 & 2 \\
\hline & Zhanjiang, Guangdong & ITS5 & 2 & 1 & NT \\
\hline & Yongan, Fujian & ITS5 & 5 & 5 & NT \\
\hline & Beihai, Guangxi & ITS5 & 8 & 8 & NT \\
\hline Punica granatum, Eryobotrya japonica & Mengzi, Yunnan & ITS5 & 5 & 5 & NT \\
\hline Colocasia esculenta & Kunming, Yunnan & ITS5 & 3 & 3 & NT \\
\hline$P$. granatum & Panzhihua, Sichuan & ITS5 & 6 & 4 & 2 \\
\hline Ipomoea batatas & Six provinces & ITS1a (AY157956) & 10 & 10 & NT \\
\hline \multicolumn{6}{|l|}{ C. cercfabiensis } \\
\hline \multirow[t]{3}{*}{ Eucalyptus sp. } & Lingao, Hainan & Asian clade (KP727593) & 5 & 0 & NT \\
\hline & Zhanjiang, Guangdong & Asian clade & 6 & 0 & NT \\
\hline & Kunming, Yunnan & Asian clade (KJ511481) & 6 & 0 & NT \\
\hline
\end{tabular}

a ITS haplotype, with representative GenBank number in parentheses.

b Tested for sexual compatibility.

${ }^{\mathrm{c}}$ Field isolates were paired with a MAT1 tester strain of $C$. fimbriata that produced pale perithecia.

d Field isolates of $C$. fimbriata that failed to pair with the MAT1 tester strain of $C$. fimbriata were paired with a MAT2 strain of $C$. fimbriata in a separate test. One isolate, from Qingyuan, Guangdong, was MAT2 by the polymerase chain reaction test but was not compatible with either the MAT1 or MAT2 tester strains. An isolate from Zhanjian, Guangdong produced perithecia when crossed with the MAT-1 tester but only watery masses of ascospores were produced. NT $=$ not tested or not determined. 
5 isolates (CERC2487 to $-91=$ C3296 to -3300 ) from one stump in Lingao City, Hainan Province; 5 isolates (CERC2125 to $-9=\mathrm{C} 3291$ to -5 ) from one stump in Yongan City, Fujian Province; 8 isolates (CERC2009 to -14 and CERC2016 to $-7=\mathrm{C} 3262$ to -9 ) from one stump in Beihai City, Guangxi Province; 5 isolates (CERC3345 to $-9=$ C3346 to -50 ) from one stump in Qingyuan City, Guangdong Province; and 8 isolates (CERC2545 to $-52=\mathrm{C} 3350$ to -4 and C3303 to -5 ) from one stump in Zhanjiang City, Guangdong Province, which is $480 \mathrm{~km}$ from Qingyuan.

Six isolates of a Ceratocystis sp. were obtained from leaves or twigs of three Eucalyptus trees on the campus of the Yunnan Agricultural University in Kunming ( $\mathrm{Li}$ et al. 2014b). Each isolate was obtained by placing discolored host tissue on PDA.

ITS rDNA barcoding. DNA was extracted from isolates grown on malt yeast extract agar (MYEA; $2 \%$ malt extract, $0.2 \%$ yeast extract, and 2\% agar) for 8 to 10 days at room temperature using the Wizard Genomic DNA Purification Kit (Promega Corporation, Madison, WI). The ITS sequences of 40 new Chinese isolates were

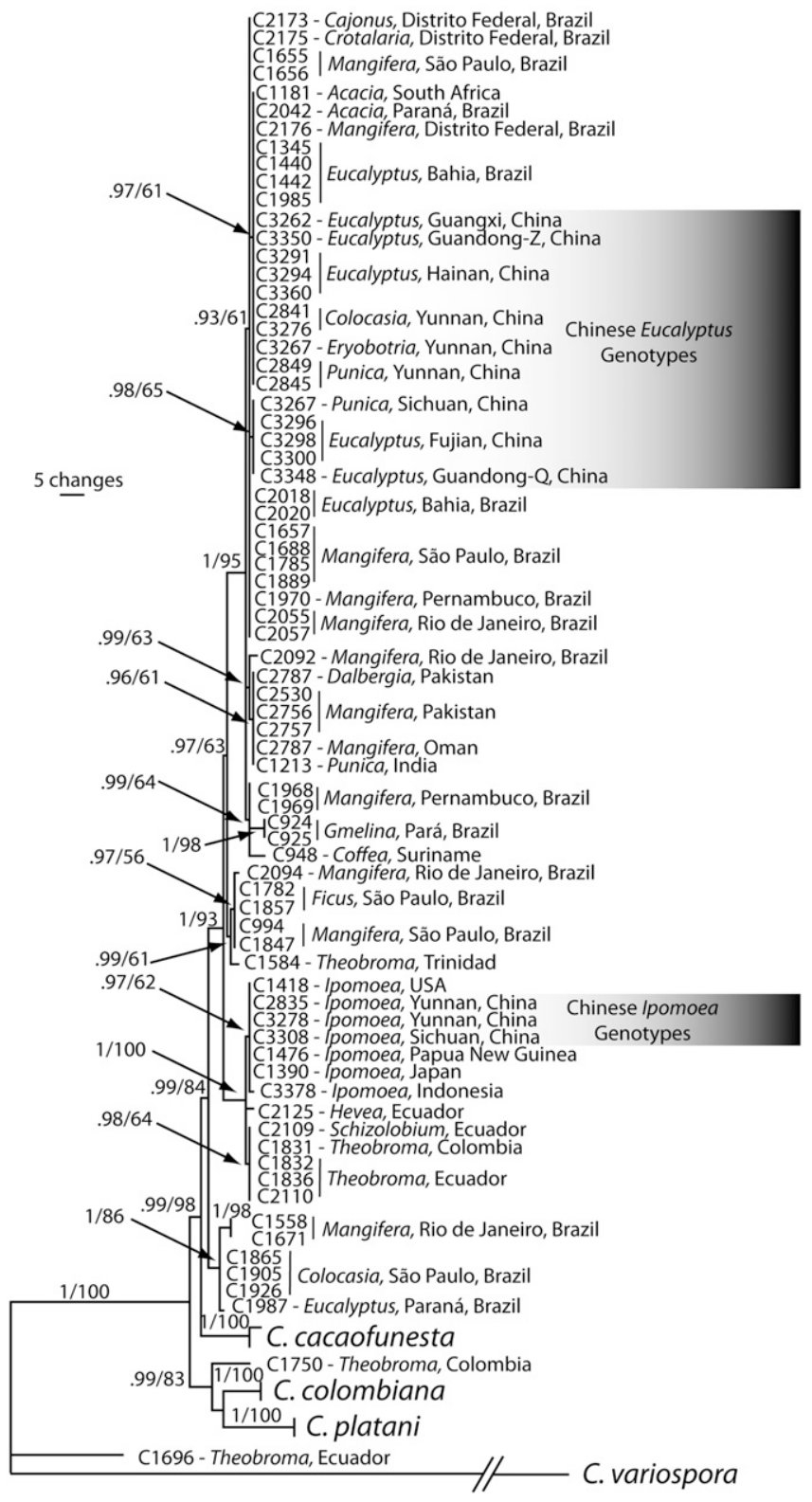

Fig. 2. One of three most-parsimonious trees of 523 steps of members of the Latin American clade of the Ceratocystis fimbriata complex, including C. fimbriata isolates from China, using MAT1 and MAT2 mating type gene sequences. C. variospora is used as the outgroup taxon. Posterior probability values of 0.9 and greater and bootstrap values $50 \%$ or greater and are indicated on the appropriate branches. determined using primers ITS1-F and ITS-4, as previously described (Harrington et al. 2014; Thorpe et al. 2005). The generated sequences were aligned by eye to a large dataset of sequences of more than 800 isolates of the $C$. fimbriata complex collected from throughout the world (Harrington et al. 2014), including the 41 isolates from pomegranate, taro, and loquat in Yunnan studied earlier (Harrington et al. 2015).

Interfertility tests. Mating studies were conducted with all of the Chinese isolates in order to determine whether they were of a single biological species (Ferreira et al. 2010; Oliveira et al. 2015b). Most field isolates of $C$. fimbriata are of the MAT2 mating type, which are capable of unidirectional mating type switching and, thus, are self-fertile and cannot readily be used in mating studies (Harrington and McNew 1997; Witthuhn et al. 2000). Single ascospore strains of the MAT1 mating type form protoperithecia and are self-sterile, and these strains can be used as female testers in pairings, providing that mature perithecia derived from crossings can be distinguished from perithecia derived from selfings of the MAT2 tester strains. In this study, we utilized a pale mutant (tester strain C3315) as a female and spermatized the tester with each of the Chinese field isolates. This MAT1 tester produced pale protoperithecia (instead of the normal black) and pale perithecia with ascospores when successfully spermatized by a MAT2 field isolate. Perithecia formed from selfings of the field isolate were the normal black color.

The female tester (C3315) in the initial crosses was derived from a self-fertile field isolate (C3223) from a wilted pomegranate tree in Karnataka, India (Somasekhara 1999). A similar strain from this area (C1213) was shown to be genetically identical to C3223 and other C. fimbriata strains from Pakistan and Oman (Harrington et al. 2014; Oliveira et al. 2015b), which were sexually compatible with a tester of $C$. fimbriata from sweet potato, as well as with Mangifera indica (mango) isolates from Brazil (Oliveira et al. 2015b). The Indian field isolate initially produced normal, black perithecia but C3240 was recovered from an ascospore mass that had collected on top of a lightly pigmented (pale) perithecium in a $\mathrm{V}$-shaped sector that produced lighter mycelium. Strain C3240 was self-fertile and produced only pale perithecia. Strain C3315 was a single-ascospore progeny from C3240 that produced pale protoperithecia but no perithecia. Polymerase chain reaction (PCR) testing (Oliveira et al. 2015b) confirmed that $\mathrm{C} 3315$ had lost the MAT2 gene (MAT1-2-1) in unidirectional mating type switching and, thus, was MAT1 in phenotype.

In total, 71 field isolates from China were tested for sexual compatibility with the MAT1 tester strain, which was first grown on MYEA for 7 days at room temperature and lighting for the production of protoperithecia. The male testers (field isolates) were grown on MYEA for 8 to 11 days, when a suspension of conidia, conidiophores, and mycelial fragments was scraped from the surface in $10 \mathrm{ml}$ of sterile water (Ferreira et al. 2011; Oliveira et al. 2015b). An aliquot of $1 \mathrm{ml}$ of the suspension was dispersed over the mycelium on onehalf of the female tester plate. The spermatized plates were incubated at room temperature and lighting for 7 to 10 days and examined through a dissecting scope for the presence of perithecia and ascospores. The perithecium is formed by the female, and the production of pale perithecia with creamy ascospore masses was considered to be due to a cross between a male/black/MAT2 field isolate and the female/pale/MAT1 tester strain (Fig. 1). Black perithecia with normal ascospore masses were considered to be the result of selfing by the male field isolate and not considered a cross. Formation of pale perithecia with watery ascospore masses was considered to be an interspecific hybrid cross (Engelbrecht and Harrington 2005; Ferreira et al. 2011; Johnson et al. 2005; Oliveira et al. 2015b).

At least one ascospore mass from each putative crossing was sampled to confirm that there had been recombination of phenotypes (a mixture of parental and nonparental phenotypes among the progeny). A creamy ascospore mass was collected from one of the pale perithecia and placed into a drop of Isopar $\mathrm{M}$ to disperse the spores, and then the ascospore mass was streaked across an MYEA plate (Ferreira et al. 2011). Streaks of ascospore masses from an interfertile cross produced colonies of differing phenotype, some MAT1/self-sterile and others MAT2/self-fertile. In cases of an interfertile cross, 
progeny from a single ascospore mass produced four colony types: self-fertile with recombinant pale perithecia with ascospores masses (pale/MAT2, nonparental type), black perithecia with ascospore masses (black/MAT2, the male type), and self-sterile (MAT1) colonies that produced either pale protoperithecia (the female type) or black protoperithecia (nonparental type).

Phylogenetic analyses. Sequences of portions of the MAT1-1-2 gene (1,022 bp) and the adjacent MAT1-2-1 gene (1,102 bp) were generated as described by Harrington et al. (2014). The sequences (MAT1-1-2/MAT1-2-1) of representative isolates from the Chinese populations were compared with sequences (GenBank accession numbers KF482983 to $-96 / \mathrm{HQ} 157549$ to -53 and KF482997 to -3004$)$ from an earlier study of the $C$. fimbriata complex (Harrington et al. 2014), which included representatives from Brazil and others of the LAC. Sequences of isolate C2109 from Schizolobium parahyba (KX229729/KX229730), isolate C2125 from Hevea brasiliensis (KX236162/KX236165), and several isolates from Theobroma cacao from Ecuador and Colombia were added to the Harrington et al. (2014) dataset because they appeared to be similar to sequences from the Ipomoea isolates from China.

The sequenced portions of the MAT1-1-2 and MAT1-2-1 genes are tightly linked and nonrecombining within the mating type locus of self-fertile isolates (Wilken et al. 2014; Witthuhn et al. 2000), and the sequences were combined in the phylogenetic analyses (Harrington et al. 2014; Oliveira et al. 2015b). The sequences in the combined dataset were readily aligned by eye, except for some minor ambiguity in alignment with the outgroup taxon, $C$. variospora, which is a member of the North American clade of the $C$. fimbriata complex (Johnson et al. 2005). The aligned dataset was analyzed by maximum parsimony using PAUP 4.0b10 (Sinauer Associates, Sunderland, MA), with settings as described by Harrington et al. (2014). Bootstrap values using 1,000 replicates also were determined in PAUP. Posterior probability estimates were determined using Mr. Bayes 3.2.1 (Ronquist and Huelsenbeck 2003), with 1,000,000 generations, diagnosis frequency $=5,000$, sample frequency $=500$, and burninfrac $=$ 0.25 .

Microsatellite markers. Fourteen microsatellite loci (AAG8, AAG9, CAA9, CAA10, CAA15, CAA38, CAA80, CAT1, CAT1200, CAG5, CAG15, CAG900, GACA60, and GACA650) were analyzed as described by Ferreira et al. (2010) using the primers developed by Steimel et al. (2004). Each pair of specific primers flanked an SSR region of 3 or $4 \mathrm{bp}$. One of the primers was fluorescently labeled, and the band sizes were determined using Peak Scanner Software v.1.0. Each product length (within $1 \mathrm{bp}$ ) was considered a different allele, though most alleles differed by increments of $3 \mathrm{bp}$.

Each unique combination of microsatellite alleles was considered a genotype. The relationships among the Chinese genotypes and other representative genotypes of the LAC of the $C$. fimbriata complex (Ferreira et al. 2010, Oliveira et al. 2015b) were determined in PAUP using the unweighted pair group method with arithmetic means (UPGMA; total character difference) and 1,000 bootstrap replications.

To compare genotypic diversity values among populations with different sample sizes, Stoddart and Taylor's genotypic diversity $(G)$ (Stoddart and Taylor 1988) was calculated as the expected number of genotypes for the smallest sample size being compared based on rarefaction curves (Grünwald et al. 2003) using the vegan package from CRAN in R v.2.6.1 (R Development Core Team 2007). For comparing $G$ at different locations, the smallest sample size was $n=5$, and comparisons of populations on the three main hosts (Ipomoea isolates, Eucalyptus isolates, and isolates from the other hosts) used $n=12$ as the smallest population size. Nei's genetic diversity $(H)$ values for the host populations were calculated with and without clone correction (which counts each genotype in a population only once) using PopGene 1.32 software (University of Alberta, Edmonton, Canada).

\section{Results}

ITS rDNA barcoding. Each of the 17 tested isolates from sweet potato, including 4 from China (1 from Yunnan, 1 from Zhejiang, and 2 from Hebei), had the identical ITS rDNA sequence (Table 1).
When aligned with the worldwide collection of isolates, this sequence was identical to sequences AY157956 and AY157957, referred to as the ITS1a haplotype, which has only been identified in Ipomoea isolates (Harrington et al. 2014). The other 13 tested Ipomoea isolates included 5 from the United States (including 1 from Hawaii), 1 from New Zealand, 2 from Papua New Guinea, 2 from Indonesia, and 3 from Japan, and each had the unique ITS1a sequence. The ITS1a haplotype was also found in a herbarium collection (BPI596219) of C. fimbriata on a sweet potato root from Saint Vincent and Grenadines (Baker et al. 2003).

Forty-one isolates from pomegranate, loquat, and taro in Yunnan were earlier sequenced for ITS, and each had the same sequence (= AM292204 to -5, AM293381 to -3 , AM690767, AM712445 to -8, AY157966, and FJ236715) (Harrington et al. 2015), referred to earlier as ITS5, a sequence commonly found among Eucalyptus isolates of C. fimbriata in Brazil (Harrington et al. 2014). Six newly tested isolates from pomegranate in Sichuan also had the ITS5 sequence, as did 30 Eucalyptus stump isolates from Qionghai, Hainan (10 isolates), Fujian (5 isolates), Guangxi (8 isolates), Zhanjiang, Guangdong (2 isolates), and Qingyuan, Guangdong (5 isolates) (Table 1).

In all, 5 of 10 isolates (CERC2165 to -9) from Eucalyptus stumps in Lingao, Hainan and 6 of 8 isolates (CERC2547 to -52) from a stump in Zhanjiang, Guandong had ITS sequences that were most similar to the sequences (KP727583 to -94) of C. cercfabiensis (Table 1), a member of the Asian clade of the $C$. fimbriata complex (Liu et al. 2015). In total, 3 of 11 isolates (CERC2168, CERC2549, and CERC2552 = C3353, C3354, and C3305, respectively) were used in the earlier study (Liu et al. 2015) as representatives of $C$. cercfabiensis. Consistent with the report of Liu et al. (2015), the electropherograms of ITS sequences of the 11 isolates from Hainan and Guandong were difficult to read by direct sequencing, apparently because of a mixture of sequences among the tandem repeats of rDNA (Harrington et al. 2014).

The six Eucalyptus isolates from leaves and twigs in Yunnan (C3371 to -6 = E2-1-1, E2-1-2, E2-2-1, E2-2-2, E2-3-1, and E2-3-2, respectively) had an ITS rDNA sequence that matched the sequence (KJ511481) of the reported cause of a wilt disease on Eucalyptus sp. in Yunnan ( $\mathrm{Li}$ et al. 2014b). This ITS sequence was similar to those of $C$. cercfabiensis isolates (e.g., KP727593), the sequences (AY526306 to -7) of isolates of an unidentified Ceratocystis sp. from taro in Hawaii and China (Thorpe et al. 2005), and sequences (AY528970 to -3) of C. polychroma from Indonesia (van Wyk et al. 2004).

Interfertility tests. Seventy-one field isolates from China were crossed with the self-sterile, MAT1, pale female tester strain from India. Forty-seven of the field isolates were fully interfertile with the $C$. fimbriata tester in the initial cross (Table 1). In each successful cross, the spermatized protoperithecia of the female tester produced many pale perithecia with large, creamy ascospore masses at the tip of the perithecial neck (Fig. 1). Samples taken from creamy ascospore masses were mounted on microscope slides with cotton-blue staining, and the ascospores appeared normal at $\times 500$ magnification (Engelbrecht and Harrington 2005; Oliveira et al. 2015b).

Germination percentages of ascospores from creamy ascospore masses were high when the spore mass was dispersed in oil and spread over MYEA plates. The colonies developing from these streaks varied in phenotype, indicating independent segregation for mating type (selffertile, MAT2 versus self-sterile, MAT1) and perithecia pigmentation (black versus pale perithecia). Based on this criterion, each of the 10 tested Ipomoea isolates from China successfully mated with the pale/ MAT1 tester (Table 1). Each of the three new isolates from taro also mated with the MAT1 tester. Of the 11 tested isolates from pomegranate (5 from Yunnan and 6 from Sichuan), 9 crossed with the MAT1 tester but 2 of the pomegranate isolates from Sichuan failed to induce perithecia production. These field isolates (C3365 and C3366) were self-sterile, and PCR analysis using MAT2 primers (Oliveira et al. 2015b) indicated that they had lost the MAT1-2-1 gene. Crossing C3365 and C3366 as females with the pale/MAT2 tester (C3240) as a male produced both black perithecia and pale perithecia in each case, and both types of perithecia had normal ascospore masses (Table 1). Streaking out an ascospore mass from a black perithecium from each cross produced colonies that were self-fertile, with either black or pale 
perithecia, and the self-sterile colonies produced either black or pale protoperithecia, thus confirming that C3365 and C3366 were both MAT1 and the same biological species as $C$. fimbriata.

Of the 30 Chinese isolates from Eucalyptus with the ITS5 sequence of $C$. fimbriata, 25 were interfertile when crossed with the pale/MAT1 tester strain (Table 1). Four of the five exceptional field isolates were self-sterile; therefore, it was suspected that they were MAT1. Three of these isolates (C3292 from Qionghai, Hainan, and C3345 and C3349 from Qingyuan, Guandong) lacked the MAT12-1 gene as determined by PCR analysis (Oliveira et al. 2015b), and these three isolates successfully crossed with the pale/MAT2 tester (C3240) of C. fimbriata (Table 1). A fourth Eucalyptus isolate (C3346 from Qingyuan) was also self-sterile but it failed to cross with either the pale/MAT1 or the pale/MAT2 tester strains, indicating that it had lost sexual compatibility. The fifth Eucalyptus isolate (C3351) was self-fertile but induced watery ascospore masses on pale perithecia when paired with $\mathrm{C} 3315$, indicating that it was not a fully interfertile cross.

The 17 isolates from Eucalyptus with ITS sequences other than ITS5 were not interfertile with the pale tester strains of $C$. fimbriata (Table 1). One isolate from a Eucalyptus stump in Lingao, Hainan was self-sterile, and no pale perithecium was produced in the crossing with the pale/MAT1 tester of $C$. fimbriata. However, the other four tested isolates from Lingao, six isolates from a Eucalyptus stump in Zhanjiang, Guandong, and the six Eucalyptus isolates from Yunnan were self-fertile and induced production of pale perithecia with watery ascospore masses when paired with the pale/MAT1 tester of $C$. fimbriata. Streaking the watery ascospore masses on MYEA found no germination of spores. Consistent with other pairings among Ceratocystis spp. (Engelbrecht and Harrington 2005; Ferreira et al. 2011; Harrington and McNew 1998; Harrington et al. 2002; Johnson et al. 2005; Oliveira et al. 2015b), the production of perithecia with watery ascospore masses was considered indicative of a hybrid crossing between two different species; namely, C. cercfabiensis $\times$ C. fimbriata.

Phylogenetic analyses. Only three different mating type gene sequences (combined MAT1-1-2/MAT1-2-1 sequences) were identified among the typical $C$. fimbriata isolates from China. The aligned dataset of 2,158 characters of the mating type genes showed 1,682 characters constant, 359 characters parsimony uninformative, and 117 characters parsimony informative. Only three most-parsimonious trees of 523 steps were found, with a consistency index of 0.9541 (0.8452 excluding uninformative characters), homoplasy index of 0.0459 ( 0.1548 excluding uninformative characters), retention index of 0.9537 , and rescaled consistency index of 0.9099 . The consensus tree from the Mr. Bayes analysis (not shown) was identical to the maximum parsimony tree shown in Figure 2.

The three sequenced Chinese isolates from sweet potato had identical sequences (KX236160/KX236164), which matched those of other Ipomoea isolates from the United States, Papua New Guinea, and Japan (KF482992/KF483000), but the tested Ipomoea isolate from Indonesia differed at one base position in the MAT1-1-2 sequence (KX236161) from the sequence of the other Ipomoea isolates. The Ipomoea isolates from China and elsewhere were found in a well-supported clade with isolates from various hosts in Ecuador and Colombia (Fig. 2).

Fifteen sampled isolates from China with the ITS5 haplotype had one of two mating type sequences. In all, 10 of the isolates had the previously reported MAT3a sequence (KX236158/KX236163, which matches KF482985/ HQ157550), and 5 had the previously reported Mat3b sequence, which has a unique base substitution in one of the MAT1-1-2 introns (KX236159, which matches KF482986), as reported earlier in a taro isolate from Yunnan (Harrington et al. 2014, 2015). The five isolates with the Mat3b sequence were from Sichuan, Fujian, and Guandong (Fig. 2). Consistent with the earlier study of Yunnan isolates (Harrington et al. 2015), all Chinese isolates with the ITS5 haplotype grouped with Brazilian isolates of $C$. fimbriata from Eucalyptus spp., mango, Acacia spp., and other hosts (Fig. 2).

The atypical isolates from China that did not mate with the pale tester of $C$. fimbriata, and had ITS sequences more typical of Asian members of the $C$. fimbriata complex (Table 1), also had MAT1-2-1 and MAT1-1-2 sequences that were more similar to those of members of the Asian clade and clearly outside of the LAC (data not shown).

Microsatellite diversity. Of the 14 tested microsatellite loci, 11 were polymorphic among the typical $C$. fimbriata isolates from China (Table 2). Three loci were monomorphic: AAG9 = 397 bp, CAG900 = $194 \mathrm{bp}$, and GACA60 = $187 \mathrm{bp}$. Some of the microsatellite primer pairs produced PCR products using DNA extracted from the Chinese Eucalyptus isolates that had ITS sequences typical of $C$. cercfabiensis in the Asian clade of the $C$. fimbriata complex but the microsatellite alleles differed substantially from those identified in isolates with the ITS1a and ITS5 haplotypes, and these atypical alleles were not analyzed further.

Populations of $C$. fimbriata on the different host groups were compared using $G$ and measures of $H$. The Ipomoea population in China had the lowest values for $G(3.00)$ and $H(0.0466$, and $H=0.0635$ with clone correction; Table 3 ). The highest values of $G$ and $H$ in China were found in the country-wide Eucalyptus population (including only isolates with the ITS5 haplotype; Table 3). The combined population of isolates from Yunnan and Sichuan on pomegranate,

Table 2. Number of isolates, microsatellite alleles (approximate size, in base pairs) for 11 polymorphic loci, and genotypic diversity found in nine Ceratocystis fimbriata populations in China

\begin{tabular}{|c|c|c|c|c|c|c|c|c|}
\hline \multirow[b]{2}{*}{ Location } & \multirow[b]{2}{*}{ Hosts } & \multirow[b]{2}{*}{$N^{\mathbf{b}}$} & \multirow[b]{2}{*}{ Iso $^{c}$} & \multicolumn{5}{|c|}{ Size of alleles ${ }^{a}$} \\
\hline & & & & AAG8 & CAA9 & CAA10 & CAA15 & CAA38 \\
\hline Qionghai, Hainan & Eucalyptus sp. & 3 & 10 & 180 & $172(5), 175(5)$ & $131(9), 134(1)$ & $318(9), 321(1)$ & $211(1), 238(9)$ \\
\hline Qingyuan, Guangdong & Eucalyptus sp. & 1 & 5 & 180 & 172 & $131(3), 134(2)$ & $318(3), 321(2)$ & $211(1), 238(4)$ \\
\hline Zhanjiang, Guangdong & Eucalyptus sp. & 1 & 2 & 180 & 175 & 134 & 324 & 238 \\
\hline Yongan, Fujian & Eucalyptus sp. & 1 & 5 & 180 & 175 & 134 & 324 & 340 \\
\hline Beihai, Guangxi & Eucalyptus sp. & 1 & 8 & 180 & 175 & 134 & 321 & 238 \\
\hline Mengzi, Yunnan & $\begin{array}{l}\text { Punica granatum, } \\
\text { Eryobotrya } \\
\text { japonica }\end{array}$ & 34 & 34 & 180 & 172 & 134 & 324 & $201(1), 238(32), 247$ (1) \\
\hline Kunming, Yunnan & Colocasia esculenta & 9 & 9 & 180 & 172 & 134 & 324 & $238(8), 247(1)$ \\
\hline Panzhihua, Sichuan & $P$. granatum & 6 & 6 & 180 & 172 & 134 & 324 & $238(4), 247(2)$ \\
\hline Six provinces & Ipomoea batatas & 12 & 12 & $174(9), 186(3)$ & $206(10), 209(2)$ & 134 & 321 & $\begin{array}{c}150 \\
\text { (continued on next page) }\end{array}$ \\
\hline
\end{tabular}

\footnotetext{
${ }^{a}$ Numbers in parentheses are the number of isolates with that allele in that population.

b Total number of plants.

c Number of isolates studied.

d Number of genotypes.

e Values of Stoddart and Taylor's genotypic diversity $(G)$ with rarefaction range from 1 (only one genotype) to 5 (each isolate a unique genotype) based on 14 microsatellite loci. $\mathrm{ND}=$ not determined, sample size.
} 
loquat, and taro had alleles similar to the Eucalyptus-ITS5 isolates from China but showed very low values of diversity $(G=3.71$ and $H=0.0537$, or $H=0.0991$ when clone corrected).

Isolates from sweet potato from all locations around the world differed at only two microsatellite loci (Table 2). Three Ipomoea genotypes $(\mathrm{C} 1, \mathrm{C} 2$, and $\mathrm{C} 3)$ were found among the 12 isolates from sweet potato in China, and these genotypes grouped closely in the UPGMA dendrogram (Fig. 3). In total, 1 of the Yunnan isolates had a combination of microsatellite alleles (the $\mathrm{C} 1$ genotype) identical to 1 of the Japanese isolates and the 19 Ipomoea isolates outside of China and Japan. Nine isolates from sweet potato in China had the same genotype (C2) as two isolates from Japan, including C1354 (= KFCF 9210) from Kagoshima Prefecture; however, the $C 2$ genotype was not found elsewhere. Two Ipomoea isolates from Sichuan had a unique allele for CAA9 (genotype C3).

A limited number of alleles (Table 2) and only eight microsatellite genotypes were identified among the Chinese isolates with the ITS5 haplotype. These eight genotypes generally grouped with Brazilian isolates from Eucalyptus in the UPGMA analysis (Fig. 3). The isolates from pomegranate in Sichuan and the Eucalyptus isolates from Fujian had microsatellite alleles similar to those of the isolates from pomegranate, taro, and loquat in Yunnan (Table 2). The isolates from taro in Yunnan and the isolates from a single pomegranate orchard in Sichuan had more genotypic diversity than the population of isolates from pomegranate in Yunnan (Table 2).

Eucalyptus isolates with the ITS5 haplotype from Hainan and Qingyuan, Guandong showed the greatest diversity of microsatellite alleles (Table 2; Fig. 3). Four microsatellite genotypes and both MAT1 and MAT2 isolates were found among the five Qingyuan isolates from a single Eucalyptus stump. In contrast, only one genotype was found among eight isolates from a stump in Guangxi (Table 1, Fig. 3). Also, only one genotype was found among the five isolates from a Eucalyptus stump in Fujian (Table 1), and this genotype was very similar to the genotypes found on pomegranate, taro, and loquat in China (Table 2; Fig. 3).

\section{Discussion}

Although some of the Ceratocystis isolates from Eucalyptus stumps in China were placed in the Asian clade of the C. fimbriata complex and, thus, not $C$. fimbriata, the other Eucalyptus isolates and isolates associated with the pomegranate and sweet potato epidemics had either the ITS5 or ITS1a haplotypes of $C$. fimbriata, respectively. The limited rDNA diversity in China is in stark contrast to populations of $C$. fimbriata in South America (Harrington et al. 2014), and analyses of microsatellite markers also showed low genetic diversity for the Chinese populations. Phylogenetic analyses placed the pomegranate and sweet potato isolates from China among members of the LAC of the C. fimbriata complex; specifically, to populations that appear to be native to eastern and northern South America, respectively.

Remarkably, the worldwide collection of $C$. fimbriata isolates from sweet potato consists of just three microsatellite haplotypes (all found in China), and these isolates share unique sequences of ITS rDNA (haplotype ITS1a), MAT1-1-2, and MAT1-2-1. An earlier study (Baker et al. 2003) found that a limited collection of Ipomoea isolates from the United States, New Zealand, Papua New Guinea, and Japan, as well as a herbarium specimen from the island of St. Vincent, had the same ITS sequence, and there appeared to be only limited variation in microsatellite alleles among the isolates (Steimel et al. 2004). Analyses of isolates from China and Indonesia and other new isolates suggest that the worldwide Ipomoea population has gone through a severe genetic bottleneck, with just minor genetic variation, as exemplified by only two polymorphic microsatellite loci (two alleles each). Ipomoea isolates are uniquely aggressive to sweet potato and not pathogenic to other hosts in inoculation studies (Baker et al. 2003), presumably through selection for aggressiveness and pathogenic colonization of storage roots, the primary means of propagation and dispersal of this important root crop (Engelbrecht and Harrington 2005; Harrington et al. 2011). Centuries of sweet potato cultivation may have resulted in selection of this host-specific strain from what is generally considered a species with a broad and unpredictable host range (Harrington 2013; Harrington et al. 2011, 2014).

According to Sy (1956), the sweet potato pathogen was well established in 1905 near Kagoshima, Japan, and it was brought from there to China in 1937 by the Japanese military on storage roots of Japanese cultivars. The disease quickly spread through northern China and parts of eastern China on these Japanese cultivars, later causing annual losses of more than 1 million metric tons of storage roots (Sy 1956). In all, 9 of 12 Chinese isolates from six provinces and 2 of 3 Japanese isolates, including C1354 from Kagoshima, had the AAG8174 allele, while all other Ipomoea isolates had AAG8-186. The dominance of the AAG8-174 allele in Ipomoea isolates from China and Japan and the sudden occurrence of devastating losses due to black rot support Sy's (1956) hypothesis that the Ipomoea strain of C. fimbriata was introduced on the Japanese cultivars.

Historical records suggest that the Ipomoea strain of $C$. fimbriata originated in the eastern United States. Symptoms of black rot on sweet potato were first noted in New Jersey in 1868 and, when the disease was described in 1890 , it was already causing serious losses across the eastern United States, where cultivars from the West Indies were widely cultivated (Halsted 1890; Harter and Weimer 1929). Black rot was later reported from New Zealand, Australia, and Japan in the early 1900s, after black rot was already the most widely distributed and serious disease on sweet potato in the United States (Harter and Weimer 1929). Distribution of the pathogen on storage roots of new cultivars from the eastern United States in the late 19th and early 20th centuries likely resulted in the introduction of $C$. fimbriata to Japan and elsewhere, though today only 1 microsatellite haplotype was identified among the 10 studied Ipomoea isolates from the eastern United States.

It is possible that the Ipomoea strain of $C$. fimbriata was native to the eastern United States; however, mating studies (Ferreira et al. 2010; Oliveira et al. 2015b) and phylogenetic analyses suggest a South American origin. Sweet potato was cultivated widely in Latin America and the Caribbean in pre-Colombian times but two centers of sweet potato diversity have been identified: Ecuador/Peru and Mexico/Central America (Roullier et al. 2013). Ecuadorian isolates

Table 2. (continued from preceding page)

\begin{tabular}{|c|c|c|c|c|c|c|c|}
\hline \multicolumn{6}{|c|}{ Size of alleles ${ }^{a}$} & \multirow[b]{2}{*}{ Gen $^{\text {d }}$} & \multirow[b]{2}{*}{$G^{\mathbf{e}}$} \\
\hline CAA80 & CAT1 & CAT12 & CAGDL5 & CAG15 & GACA650 & & \\
\hline $311(1), 317(9)$ & 261 & 377 & 320 & $259(5), 262(5)$ & 215 & 4 & 2.91 \\
\hline 311 & 261 & 377 & 317 & $259(1), 262(4)$ & 215 & 4 & 4.00 \\
\hline 311 & 261 & 377 & 320 & 259 & 215 & 1 & ND \\
\hline 317 & 261 & 377 & 320 & 262 & 215 & 1 & 1.00 \\
\hline 311 & 261 & 377 & 320 & 259 & 215 & 1 & 1.00 \\
\hline $311(5), 317$ (29) & 261 & 377 & 320 & $262(33), 271(1)$ & 215 & 5 & 2.01 \\
\hline $311(6), 317(1), 323(2)$ & 261 & 377 & 320 & 262 & 215 & 4 & 2.94 \\
\hline $311(4), 323$ (2) & 261 & 377 & 320 & 262 & 215 & 3 & 3.00 \\
\hline 302 & 255 & 374 & 317 & 176 & 219 & 3 & 2.10 \\
\hline
\end{tabular}


of $C$. fimbriata recovered from $S$. parahyba and $T$. cacao had the same MAT1-2-1 sequence as Ipomoea isolates and differed by just two base substitutions out of 1,039 bp in their MAT1-1-2 sequences. However, a pathway for the Ipomoea strain from northwestern South America to the eastern United States in the 19th century is not clear.

Isolates of $C$. fimbriata from other hosts in China are clearly distinct genetically from the Ipomoea strain, with no evidence of introgression between the Ipomoea and Punica populations. However, the Chinese isolates of $C$. fimbriata from all hosts, including sweet potato, were sexually compatible in crosses with a tester strain of C. fimbriata from India. Thus, the cause of the current epidemic on pomegranate is the same biological species as the sweet potato pathogen. Analyses of an expanded collection of isolates from Yunnan and the addition of pomegranate isolates from Sichuan confirm that the pomegranate epidemic in China is associated with a single population of $C$. fimbriata with very limited genetic variation. The pomegranate strain has been found causing a postharvest rot on taro corms in Yunnan, and more genetic variation was found among taro isolates from just two sources in or near Kunming than among all pomegranate isolates from Yunnan and Sichuan. Taro and other species of Araceae appear to be common hosts for a wide genetic diversity of Ceratocystis spp. (Thorpe et al. 2005), and taro corms may be an important pathway for pathogen dispersal within China. C. fimbriata appears to be moving between root-grafted pomegranate trees in Mengzi, Yunnan, and taro is interplanted with pomegranate in the expanding infection centers of pomegranate mortality (T. C. Harrington, personal observation). Thus, infection of taro corms from soilborne inoculum is likely common. Loquat and many other hosts have been reported in Yunnan ( $\mathrm{Li}$ et al. 2014a) but the impact on those crops appears to be small compared with the substantial mortality found on pomegranate.

It was earlier speculated that the pomegranate epidemic in Yunnan was caused by strains introduced to China on Eucalyptus cuttings from Brazil (Harrington et al. 2015). The dominant microsatellite alleles and all sequences found in isolates from the Yunnan/Sichuan epidemic on pomegranate were found among isolates from Eucalyptus stumps in South China (Chen et al. 2013), especially the Eucalyptus isolates from Fujian. In turn, the Chinese Eucalyptus isolates of C. fimbriata have microsatellite alleles and mating type gene sequences typical for Eucalyptus strains from Brazil, where there is substantial genetic variation, typical of natural populations, and movement of $C$. fimbriata genotypes in Eucalyptus cuttings is common (Ferreira et al. 2011). Outside of China and in a few other introduced populations of $C$. fimbriata, the ITS5 haplotype only has been recovered from soil or Eucalyptus trees in Bahia, Brazil, where many other ITS haplotypes are found (Harrington et al. 2014, 2015). The limited number of microsatellite alleles found in Eucalyptus isolates from across South China suggests that there may have been several genotypes introduced directly or indirectly from Brazil. The relatively high genotypic diversity, relative to gene diversity, of the Eucalyptus isolates in China may be due to frequent recombination, perhaps due to spread of different mating types on chainsaws and other tools (Ferreira et al. 2011). The most variation in China was found among Eucalyptus isolates from Guandong and nearby Hainan, where there are extensive plantings of Eucalyptus clones, and South China has been a focus of genetic improvement in Eucalyptus clones since the 1980s (Chen et al. 2013). It remains unclear if the strains recovered from Eucalyptus stumps are aggressive on this host plant in China (Chen et al. 2013). Eucalyptus isolates with the ITS5 haplotype from Bahia, Brazil (e.g., C1345) are moderately aggressive to this host in inoculation studies, though related strains in Bahia and Minas Gerais, Brazil can be very aggressive on certain clones of hybrid Eucalyptus spp. (Baker et al. 2003; Harrington et al. 2011; Oliveira et al. 2015a; Zauza et al. 2004).

The most aggressive plant pathogens in the $C$. fimbriata complex appear to be in the LAC but members of the Asian clade of the C. fimbriata complex also have been associated with symptomatic plants. Recently, Chinese isolates from stumps of Cunninghamia lanceolata were described as Ceratocystis collisensis, and isolates from stumps of Eucalyptus were described as C. cercfabiensis (Liu et al. 2015). Our mating studies and ITS rDNA sequencing confirm that isolates considered C. cercfabiensis from Zhanjiang, Guandong and the nearby location of Lingao, Hainan are distinct from C. fimbriata and belong to the Asian clade of the complex.

Isolates from leaves and twigs of Eucalyptus in Kunming also were placed in the Asian clade by phylogenetic analyses and appear to be conspecific with $C$. cercfabiensis. These isolates had the same ITS sequence (KJ511481) and came from the same planting of trees as the isolate reported to be an aggressive wilt pathogen on Eucalyptus sp. (Li et al. 2014b). However, in 2014 (T. C. Harrington, personal observations) the affected trees showed symptoms of only a minor leaf and twig disease, not a lethal wilt.

The taxonomy of the $C$. fimbriata complex is controversial, especially among members of the LAC (Ferreira et al. 2010; Fourie et al. 2015; Harrington et al. 2011, 2014; Oliveira et al. 2015b). One approach in species recognition has been to restrict the name $C$. fimbriata to only the originally described strain on sweet potato, and other genetic variants of the fungus that can be identified by phylogenetic analyses or microsatellite alleles could be described as new species (Fourie et al. 2015). Eucalyptus isolates from China with the ITS5 sequence have been referred to as C. eucalypticola, C. acaciivora, and $C$. manginecans but these are considered synonyms of $C$. fimbriata (Harrington et al. 2014, 2015). Brazilian isolates from Eucalyptus and other hosts were interfertile with Ipomoea tester strains (Ferreira et al. 2010; Oliveira et al. 2015b) and, in this study, sweet potato, pomegranate, taro, and most Eucalyptus isolates from China were fully interfertile with an Indian strain of $C$. fimbriata from pomegranate. Thus, all the studied isolates of the LAC from China are considered $C$. fimbriata using the biological species concept.

The two historic epidemics associated with C. fimbriata in China appear to be native to different regions of South America. Vegetatively propagated plants are the typical pathway for introducing strains of C. fimbriata to new areas, and movement in sweet potato storage roots and cuttings of Eucalyptus used for clonal propagation has been common (Engelbrecht and Harrington 2005; Ferreira et al. 2011; Harrington 2013). Clonally propagated Eucalyptus trees are not common in the pomegranate-growing region in Yunnan, where most pomegranate

Table 3. Genotypic diversity and gene diversity based on 14 microsatellite loci in Ceratocystis fimbriata populations on different hosts in China

\begin{tabular}{|c|c|c|c|c|c|c|c|}
\hline \multirow[b]{2}{*}{ Hosts } & \multirow[b]{2}{*}{ Loc $^{\mathbf{b}}$} & \multicolumn{3}{|c|}{ Number of ${ }^{a}$} & \multirow[b]{2}{*}{$G^{\mathbf{c}}$} & \multicolumn{2}{|c|}{ Nei's gene diversity } \\
\hline & & $\overline{\text { Sre }}$ & Iso & $\overline{\text { Gen }}$ & & All $^{\mathrm{d}}$ & Clone $^{\mathrm{e}}$ \\
\hline Eucalyptus spp. & Four & 7 & 30 & 11 & 6.97 & 0.2306 & 0.2456 \\
\hline $\begin{array}{l}\text { Punica granatum, Eriobotrya japonica, and } \\
\text { Colocasia esculenta }\end{array}$ & Two & 49 & 49 & 7 & 3.71 & 0.0537 & 0.0991 \\
\hline Ipomoea batatas & Six & 12 & 12 & 3 & 3.00 & 0.0466 & 0.0635 \\
\hline
\end{tabular}


trees are propagated from air layering of cuttings from local trees. It is unclear how the pomegranate strains may have arrived in Yunnan and Sichuan from regions with clonal Eucalyptus plantings, although propagation using taro corms is one possibility (Thorpe et al. 2005) and warrants further study.
Movement of $C$. fimbriata in cuttings of Eucalyptus clones continues to be a major threat to this and many other crop species because of the broad and unpredictable host range of most $C$. fimbriata strains (Harrington 2013; Harrington et al. 2011). The sweet potato pathogen appears to be host specialized, and black rot is now more effectively

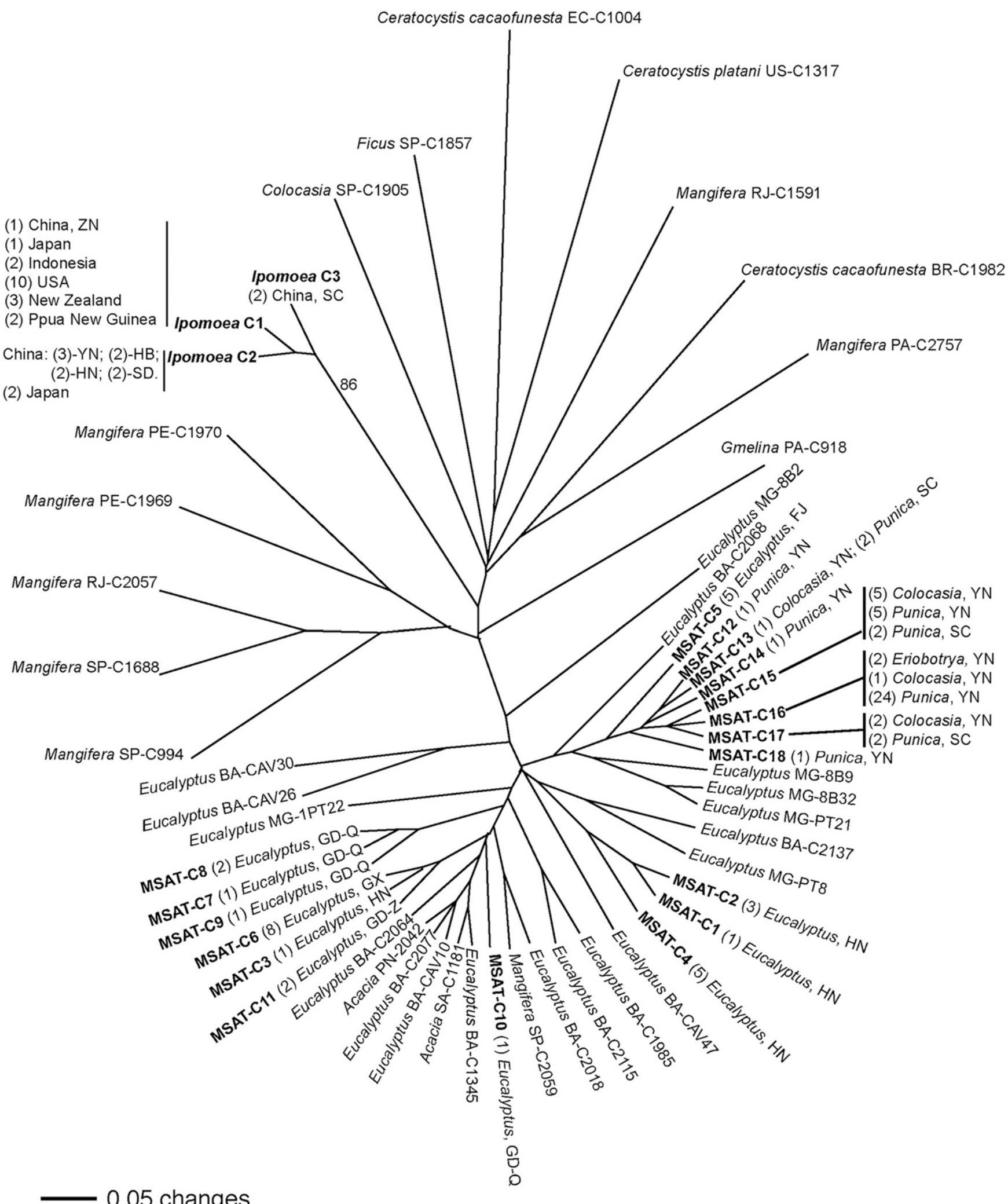

Fig. 3. Dendrogram of the genetic relatedness of representative microsatellite genotypes of Ceratocystis cacaofunesta, C. platani, and C. fimbriata, including 3 genotypes designated in bold (Ipomoea C1 to C3) from Ipomoea batatas and 18 genotypes (MSAT-C1 to MSAT-C18) from other hosts in China. Host and province (China), state (Brazil), or country of origin are given for each genotype (number of isolates with that genotype in parentheses). The dendrogram was generated by the unweighted pair group method with arithmetic means and total character distance was based on 14 microsatellite markers. Bootstrap values from 1,000 replications are shown alongside the branches. 
managed and appears to be less important than in the past. However, the epidemic on pomegranate continues unabated in China and new, economically important hosts may be recognized in the future.

\section{Acknowledgments}

Q. Li's work was supported by the National Natural Science Foundation of China (grant numbers 31571958 and 31071726) and the China Scholarship Council Fund, and she is currently a joint postdoc of the China Agricultural University and Haidian Science Park (postdoc number 167004). The work also was supported by Vale SA, Brazil. We thank A. Gafur (Riau Andalan Pulp \& Paper, Indonesia), G. Sun (Biotech Lab of the Institute of Plant Protection, Henan Academy of Agricultural Sciences), C. Suarez (Universidad Técnica Estatal de Quevedo, Ecuador), and many others who provided valuable isolates for this study; and L. Oliveira and D. Valdetaro for technical assistance and advice.

\section{Literature Cited}

Baker, C. J., Harrington, T. C., Krauss, U., and Alfenas, A. C. 2003. Genetic variability and host specialization in the Latin American clade of Ceratocystis fimbriata. Phytopathology 93:1274-1284.

CABI. 2005. Ceratocystis fimbriata. In: Crop Protection Compendium. Online publication. CAB International, Wallingford, UK. www.cabi.org/cpc

Chen, S. F., van Wyk, M., Roux, J., Wingfield, M. J., Xie, Y. J., and Zhou, X. D. 2013. Taxonomy and pathogenicity of Ceratocystis species on Eucalyptus trees in South China, including C. chinaeucensis sp. nov. Fungal Divers. 58:267-279.

de Beer, Z. W., Duong, T. A., Barnes, I., Wingfield, B. D., and Wingfield, M. J. 2014. Redefining Ceratocystis and allied genera. Stud. Mycol. 79:187-219.

Engelbrecht, C. J. B., and Harrington, T. C. 2005. Intersterility, morphology, and taxonomy of Ceratocystis fimbriata on sweet potato, cacao, and sycamore. Mycologia 97:57-69.

Engelbrecht, C. J. B., Harrington, T. C., Alfenas, A. C., and Suarez, C. 2007. Genetic variation of populations of the cacao wilt pathogen, Ceratocystis cacaofunesta. Plant Pathol. 56:923-933.

Engelbrecht, C. J. B., Harrington, T. C., Steimel, J., and Capretti, P. 2004. Genetic variation in eastern North American and putatively introduced populations of Ceratocystis fimbriata f. sp. platani. Mol. Ecol. 13:2995-3005.

Ferreira, E. M., Harrington, T. C., Thorpe, D. J., and Alfenas, A. C. 2010. Genetic diversity and interfertility among highly differentiated populations of Ceratocystis fimbriata in Brazil. Plant Pathol. 59:721-735.

Ferreira, M. A., Harrington, T. C., Alfenas, A. C., and Mitzubuti, E. S. G. 2011. Movement of genotypes of Ceratocystis fimbriata within and among Eucalyptus plantations in Brazil. Phytopathology 101:1005-1012.

Fourie, A., Wingfield, M. J., Wingfield, B. D., and Barnes, I. 2015. Molecular markers delimit cryptic species in Ceratocystis sensu stricto. Mycol. Prog. 14:1020.

Grünwald, N. J., Goodwin, S. B., Milgroom, M. G., and Fry, W. E. 2003. Analysis of genotypic diversity data for populations of microorganisms. Phytopathology 93:738-746.

Halsted, B. D. 1890. Some fungous diseases of the sweet potato. The black rot. Bull. N. J. Agric. Exp. Stn. 76:7-14.

Harrington, T. C. 2000. Host specialization and speciation in the American wilt pathogen Ceratocystis fimbriata. Fitopatol. Bras. 25 (Suppl.):262-263.

Harrington, T. C. 2013. Ceratocystis diseases. Pages 230-255 in: Infectious Forest Diseases. P. Gonthier and G. Nicolotti, eds. CAB International, Wallingford, UK.

Harrington, T. C., Huang, Q., Ferreira, M., and Alfenas, A. C. 2015. Genetic analyses trace the Yunnan, China population of Ceratocystis fimbriata on pomegranate and taro to populations on Eucalyptus in Brazil. Plant Dis. 99:106-111.

Harrington, T. C., Kazmi, M. R., Al-Sadi, A. M., and Ismail, S. I. 2014. Intraspecific and intragenomic variability of ITS rDNA sequences reveals taxonomic problems in Ceratocystis fimbriata sensu stricto. Mycologia 106:224-242.

Harrington, T. C., and McNew, D. L. 1997. Self-fertility and uni-directional mating-type switching in Ceratocystis coerulescens, a filamentous ascomycete. Curr. Genet. 32:52-59.

Harrington, T. C., and McNew, D. L. 1998. Partial interfertility among the Ceratocystis species on conifers. Fungal Genet. Biol. 25:44-53.

Harrington, T. C., Pashenova, N. V., McNew, D. L., Steimel, J., and Konstantinov, M. Y. 2002. Species delimitation and host specialization of Ceratocystis laricicola and C. polonica to larch and spruce. Plant Dis. 86:418-422.

Harrington, T. C., Thorpe, D. J., and Alfenas, A. C. 2011. Genetic variation and variation in aggressiveness to native and exotic hosts among Brazilian populations of Ceratocystis fimbriata. Phytopathology 101:555-566.

Harter, L. L., and Weimer, J. L. 1929. A monographic study of sweet potato diseases and their control. Tech. Bull. No. 99. United States Department of Agriculture, Washington, DC.

Huang, Q., Wang, Y. Y., Zhao, Y. Y., Jiao, Y. X., Li, X. F., Chen, H. R., and Zhu, Y. Y. 2008. First report of taro black rot caused by Ceratocystis fimbriata in China. Plant Pathol. 57:780.
Huang, Q., Zhu, Y. Y., Chen, H. R., Wang, Y. Y., Liu, Y. L., Lu, W. J., and Ruan, X. Y. 2003. First report of pomegranate wilt caused by Ceratocystis fimbriata in Yunnan, China. Plant Dis. 87:1150.

Johnson, J. A., Harrington, T. C., and Engelbrecht, C. J. B. 2005. Phylogeny and taxonomy of the North American clade of the Ceratocystis fimbriata complex. Mycologia 97:1067-1092.

Li, J., Gao, J. M., Han, Y. H., Sun, Y. X., and Huang, Q. 2014a. First report of Ceratocystis fimbriata-caused wilt of Eriobotrya japonica in China. Plant Dis. 98:1270.

Li, J., Xu, K., Yang, J., Han, Y., Sun, Y., and Huang, Q. 2014b. First report of Ceratocystis fimbriata caused wilt of Eucalyptus in China. Plant Dis. 98:1744.

Liu, F. F., Mbenoun, M., Barnes, I., Roux, J., Wingfield, M. J., Li, G. Q., Li, J. Q., and Chen, S. F. 2015. New Ceratocystis species from Eucalyptus and Cunninghamia in South China. Antonie Leeuwenhoek 107:1451-1473.

Ocasio-Morales, R. G., Tsopelas, P., and Harrington, T. C. 2007. Origin of Ceratocystis platani on native Platanus orientalis in Greece and its impact on natural forests. Plant Dis. 91:901-904.

Oliveira, L. S. S., Guimaraes, L. M. S., Ferreira, M. A., Nunes, A. S., Pimenta, L. V. A., and Alfenas, A. C. 2015a. Aggressiveness, cultural characteristics and genetic variation of Ceratocystis fimbriata on Eucalyptus spp. For. Pathol. 45:505-514.

Oliveira, L. S. S., Harington, T. C., Ferreira, M. A., Damacena, M. B., Al-Sadi, A. M., Al-Mahmooli, H. I. S., and Alfenas, A. C. 2015b. Species or genotypes? Reassessment of four recently described species of the Ceratocystis wilt pathogen, C. fimbriata, on Mangifera indica. Phytopathology 105:1229-1244.

R Development Core Team. 2007. R Foundation for Statistical Computing Vienna, Austria. Version 2.6.1, URL http://www.R-project.org/ Ronquist, F., and Huelsenbeck, J. P. 2003. MRBAYES 3: Bayesian phylogenetic inference under mixed models. Bioinformatics 19:1572-1574.

Roullier, C., Benoit, L., McKey, D. B., and Lebot, V. 2013. Historical collections reveal patterns of diffusion of sweet potato in Oceania obscured by modern plant movements and recombination. PNAS 110:2205-2210.

Somasekhara, Y. M. 1999. New record of Ceratocystis fimbriata causing wilt of pomegranate in India. Plant Dis. 83:400.

Steimel, J., Engelbrecht, C. J. B., and Harrington, T. C. 2004. Development and characterization of microsatellite markers for the fungus Ceratocystis fimbriata. Mol. Ecol. Notes 4:215-218.

Stoddart, J. A., and Taylor, J. F. 1988. Genotypic diversity: Estimation and prediction in samples. Genetics 118:705-711.

Sy, C. M. 1956. Studies on the control of black rot (Ophiostoma fimbriatum) of sweet potato. Acta Phytopathol. Sin. 2:81-95. (In Chinese, abstract in English)

Tarigan, M., Roux, J., van Wyk, M., Tjahjono, B., and Wingfield, M. J. 2011. A new wilt and dieback disease of Acacia mangium associated with Ceratocystis manginecans and C. acaciivora sp. nov. in Indonesia. S. Afr. J. Bot. 77:292-304.

Thorpe, D. J., Harrington, T. C., and Uchida, J. Y. 2005. Pathogenicity, internal transcribed spacer-rDNA variation, and human dispersal of Ceratocystis fimbriata on the family Araceae. Phytopathology 95:316-323.

van Wyk, M., Al Adawi, A. O., Khan, I. A., Deadman, M. L., Al Jahwari, A. A., Wingfield, B. D., Ploetz, R., and Wingfield, M. J. 2007. Ceratocystis manginecans sp. nov., causal agent of a destructive mango wilt disease in Oman and Pakistan. Fungal Divers. 27:213-230.

van Wyk, M., Roux, J., Nkuekam, G. K., Wingfield, B. D., and Wingfield, M. J. 2012. Ceratocystis eucalypticola sp. nov. from Eucalyptus in South Africa and comparison to global isolates from this tree. IMA Fungus 3:45-58.

van Wyk, M., van der Merve, N. A., Roux, I., Wingfield, B. D., Kamgan, G. N., and Wingfield, M. J. 2006. Population genetic analyses suggest that the Eucalyptus fungal pathogen Ceratocystis fimbriata has been introduced into South Africa. S. Afr. J. Sci. 102:259-263.

van Wyk, M., Wingfield, B. D., Al-Adawi, A. O., Rossetto, C. J., Ito, M. F., and Wingfield, M. J. 2011. Two new Ceratocystis species associated with mango disease in Brazil. Mycotaxon 117:381-404.

van Wyk, M. V., Roux, J., Barnes, I., Wingfield, B. D., Liew, E. C. Y., Assa, B., Summerell, B. A., and Wingfield, M. J. 2004. Ceratocystis polychroma sp. nov. a new species from Syzygium aromaticum in Sulawesi. Stud. Mycol. 50:273-282.

Wilken, P. M., Steenkamp, E. T., Wingfield, M. J., de Beer, Z. W., and Wingfield, B. D. 2014. DNA loss at the Ceratocystis fimbriata mating locus results in selfsterility. PLoS ONE 9(3):e92180. doi:10.1371/journal.pone.0092180.

Witthuhn, R. C., Harrington, T. C., Wingfield, B. D., Steimel, J., and Wingfield, M. J. 2000. Deletion of the MAT-2 mating-type gene during unidirectional mating-type switching in Ceratocystis. Curr. Genet. 38:48-52.

Xu, B., Zheng, X. H., Guo, W. X., Zhou, X. P., and He, P. 2011. First report of pomegranate wilt caused by Ceratocystis fimbriata in Sichuan Province. Plant Dis. 95:776.

Zauza, E. A. V., Alfenas, A. C., Harrington, T. C., Mizubuti, E. S., and Silva, J. F. 2004. Resistance of Eucalyptus clones to Ceratocystis fimbriata. Plant Dis. 88: 758-760. 